\title{
Vitamin C against the harmful effects of prenatal passive smoking: when all other options fail?
}

\author{
Peter J. Merkus (10) ${ }^{1}$ and Steve Turner (10 ${ }^{2}$ \\ Affiliations: ${ }^{1}$ Division of Respiratory Medicine and Allergology, Radboudumc Amalia Children's Hospital, \\ Nijmegen, The Netherlands. ${ }^{2}$ Child Health, Royal Aberdeen Children's Hospital, Aberdeen, UK. \\ Correspondence: Peter J. Merkus, Division of Respiratory Medicine and Allergology, Radboudumc Amalia \\ Children's Hospital, P.O. Box 9101, 6500 HB Nijmegen, The Netherlands. E-mail: Peter.Merkusaradboudumc.nl
}

@ERSpublications

Vitamin C administration to severely addicted pregnant smokers may induce a small improvement in lung function of their offspring compared to controls. To assess any clinical relevance, replicate and long-term follow-up studies are needed. https://bit.ly/2DZoVRT

Cite this article as: Merkus PJ, Turner S. Vitamin C against the harmful effects of prenatal passive smoking: when all other options fail? Eur Respir J 2020; 56: 2002770 [https://doi.org/10.1183/ 13993003.02770-2020].

\begin{abstract}
The mortality and morbidity due to cigarette smoking are gigantic. Worldwide, about 7 million people die every year ( 800 per hour!) due to a smoking-related illness and the morbidity is estimated to be about 30 times as high [1]. And though we all agree that tobacco companies making a product that eventually kills about $50 \%$ of its customers should be shut down and the product be banned, producing or selling cigarettes is not illegal yet. The tobacco industry even actively seduces "replacement smokers" to compensate for the loss of customers who died using their products [2] and the youngest, most vulnerable generation is the target of that strategy, including women who become pregnant. Apparently, cigarettes are made so addictive that worldwide about $50 \%$ of women who smoke daily even continue to smoke during pregnancy, ranging from about $30 \%$ in the European Region to about $80 \%$ in the Western Pacific Region [3]. Antenatal exposure to products of tobacco smoke during pregnancy is the most common preventable cause of infant morbidity and mortality [4]. Although exposure comes from many individuals, the most important exposure is maternal smoking. Well known complications associated with antenatal exposure to smoking include prematurity, stillbirth, antenatal growth failure [4], low birth weight [5], congenital anomalies [6] and sudden infant death syndrome [7]. Maternal prenatal smoking has a durable effect on her offspring's wellbeing, and is associated with increased risk for many noncommunicable diseases including asthma [8], increased body mass index [9] and metabolic syndrome [10], reduced lung function [11], serious conduct disorders $[12,13]$, and according to animal studies, a predisposition to nicotine addiction $[14,15]$.

Proving that exposure to tobacco smoke causes harm to the unborn child is impossible for ethical reasons, but persuasive evidence of causation comes from the drop in adverse perinatal outcomes immediately after smoke-free legislation is introduced [16]. Plausible mechanisms include in utero hypoxia, nicotine-induced nutritional deprivation and reductions in uteroplacental blood flow, placental toxicity, toxic growth restriction from the many toxicants in tobacco smoke, depressed fetal breathing movements and the direct neurotoxic effects of nicotine on the developing brain.
\end{abstract}


Clearly all efforts should be made to stop antenatal exposure to products of tobacco smoke, but when the smoking mother is not able to quit, how nice would it be if the harm from exposure could be modified by a safe and simple intervention.

Different aspects of maternal dietary intake during pregnancy have been linked to risk for perinatal outcomes and respiratory outcomes in childhood [17]. One "candidate" beneficial dietary exposure is vitamin C. Vitamin C is an anti-oxidant that helps antagonise the nicotine induced damage [18, 19], or alterations in lung metabolism [20] and there is some indication that it prevents offspring DNA methylation changes associated with maternal smoking in pregnancy [21]. Previous work also suggests that vitamin $\mathrm{C}$ can reduce the nicotine exposure induced impaired neurological functioning in rats [22], and reduce the risk of developing sudden infant death syndrome [23]. In other animal experiments vitamin $\mathrm{C}$ seems to antagonise the negative effects of prenatal exposure to nicotine on the development of the lungs $[24,25]$. Hence, the suggestion that vitamin $C$ might counteract some of the negative effects of prenatal passive smoking in humans was launched.

Published in this issue of the European Respiratory Journal, vitamin C was administered in a randomised placebo-controlled trial to smoking pregnant women to assess its effects on airway function of the offspring at the age of 12 months [26]. This paper follows on from an earlier publication from the same cohort based on infant lung function testing at the age of 3 months [27]. The mothers included had very high urinary cotinine concentrations at randomisation, so were not simply occasional smokers. Also of note, the participant's vitamin $\mathrm{C}$ concentration at recruitment were consistent with "normal" values so the intervention achieved above normal vitamin $\mathrm{C}$ exposures and did not simply supplement any vitamin $\mathrm{C}$ deficiency. The main finding was that the intervention was associated with statistically significant, but small, increases in lung function (as evidenced by forced expiratory volume in $0.5 \mathrm{~s}\left(\mathrm{FEV}_{0.5}\right)$ ) of approximately $0.2 \mathrm{z}$-scores at 3 months and of $0.1 \mathrm{z}$-scores at 12 months of age.

What are the public health implications of these findings?

First, this study provides again a level of evidence that maternal smoking is harmful to unborn children. The offspring of both study groups of smoking pregnant women had a birth weight reduction of -1 Z-score despite vitamin C supplementation. The vitamin C intervention therefore seems unlikely to palliate against the many noncommunicable diseases associated with prenatal passive smoking being small for gestational age and we should not assume that the nicotine-induced brain damage is avoided either.

Second, this provides proof-of-concept that palliation against a reduction of airway function may be possible, but further follow-up is required (ideally with replication) before these findings should be incorporated into policy. At the age of 3 months, the primary lung function end-point was not, but secondary lung function end-points were, statistically significantly different compared to the control population; and also at the age of 12 months, there was a small but statistically significant difference between groups with respect to some expiratory flow measures suggesting that airway function was increased due to the intervention compared to the control population [27]. However, in the current study, this was not associated with a between group difference in the overall incidence of composite wheeze and further follow-up should clarify whether the slightly higher forced expiratory flows are clinically relevant (i.e. result in a reduction of wheeze symptoms and/or respiratory disease in later life).

Hence, vitamin C supplementation administered to severely nicotine-addicted pregnant women who cannot quit smoking seems a safe and inexpensive measure that may improve offspring respiratory function, although the clinical relevance of this effect is not clear yet. Therefore, taking vitamin $\mathrm{C}$ can never be an excuse to continue smoking. The bigger picture is that smoking remains a social norm in too many communities and contributes to health inequalities within and between countries. The best we, as healthcare professionals, can do is help children and teenagers not to start smoking. At the (inter)national level, all efforts are required to challenge all acceptance, and break family traditions, of smoking and help future generations fight against health inequalities.

Conflict of interest: None declared.

\section{References}

1 CDC. Smoking \& tobacco use fast facts. www.cdc.gov/tobacco/data_statistics/fact_sheets/fast_facts/index.htm Date last updated: May 2020. Date last accessed: July 2020.

2 Campaign for Tobacco Free Kids. Tobacco Company Quotes on Marketing to Kids. https://www.tobaccofreekids. org/assets/factsheets/0114.pdf Date last updated: 14 May 2001. Date last accessed: July 2020.

3 Lange S, Probst C, Rehm J, et al. National, regional, and global prevalence of smoking during pregnancy in the general population: a systematic review and meta-analysis. Lancet Glob Health 2018; 6: e769-e776.

4 Abraham M, Alramadhan S, Iniguez C, et al. A systematic review of maternal smoking during pregnancy and fetal measurements with meta-analysis. PLoS One 2017; 12: e0170946. 
5 Banderali G, Martelli A, Landi M, et al. Short and long term health effects of parental tobacco smoking during pregnancy and lactation: a descriptive review. J Transl Med 2015; 13: 327.

6 Baldacci S, Gorini F, Santoro M, et al. Environmental and individual exposure and the risk of congenital anomalies: a review of recent epidemiological evidence. Epidemiol Prev 2018; 42: Suppl. 1, 1-34.

7 Kuniyoshi KM, Rehan VK. The impact of perinatal nicotine exposure on fetal lung development and subsequent respiratory morbidity. Birth Defects Res 2019; 111: 1270-1283.

8 Silvestri M, Franchi S, Pistorio A, et al. Smoke exposure, wheezing, and asthma development: a systematic review and meta-analysis in unselected birth cohorts. Pediatr Pulmonol 2015; 50: 353-362.

9 Oken E, Levitan EB, Gillman MW. Maternal smoking during pregnancy and child overweight: systematic review and meta-analysis. Int J Obes (Lond) 2008; 32: 201-210.

10 Rogers JM. Smoking and pregnancy: Epigenetics and developmental origins of the metabolic syndrome. Birth Defects Res 2019; 111: 1259-1269.

11 McEvoy CT, Spindel ER. Pulmonary effects of maternal smoking on the fetus and child: effects on lung development, respiratory morbidities, and life long lung health. Paediatr Respir Rev 2017; 21: 27-33.

12 Ruisch IH, Dietrich A, Glennon JC, et al. Maternal substance use during pregnancy and offspring conduct problems: a meta-analysis. Neurosci Biobehav Rev 2018; 84: 325-336.

13 Huang L, Wang Y, Zhang L, et al. Maternal smoking and attention-deficit/hyperactivity disorder in offspring: a meta-analysis. Pediatrics 2018; 141: e20172465.

14 Levin ED, Lawrence SS, Petro A, et al. Adolescent $v s$. adult-onset nicotine self-administration in male rats: duration of effect and differential nicotinic receptor correlates. Neurotoxicol Teratol 2007; 29: 458-465.

15 Levin ED, Lawrence S, Petro A, et al. Increased nicotine self-administration following prenatal exposure in female rats. Pharmacol Biochem Behav 2006; 85: 669-674.

16 Been JV, Mackay DF, Millett C, et al. Impact of smoke-free legislation on perinatal and infant mortality: a national quasi-experimental study. Sci Rep 2015; 5: 13020.

17 Nurmatov U, Devereux G, Sheikh A. Nutrients and foods for the primary prevention of asthma and allergy: systematic review and meta-analysis. J Allergy Clin Immunol 2011; 127: 724-733.

18 Gunes T, Koklu E, Gunes I, et al. Influence of maternal nicotine exposure on neonatal rat oxidant-antioxidant system and effect of ascorbic acid supplementation. Hum Exp Toxicol 2008; 27: 781-786.

19 Gallo C, Renzi P, Loizzo S, et al. Potential therapeutic effects of vitamin E and C on placental oxidative stress induced by nicotine: an in vitro evidence. Open Biochem J 2010; 4: 77-82.

20 Maritz GS. The influence of maternal nicotine exposure on neonatal lung metabolism. Protective effect of ascorbic acid. Cell Biol Int 1993; 17: 579-585.

21 Shorey-Kendrick LE, McEvoy CT, Ferguson B, et al. Vitamin C prevents offspring DNA methylation changes associated with maternal smoking in pregnancy. Am J Respir Crit Care Med 2017; 196: 745-755.

22 Sirasanagandla SR, Rooben RK, Rajkumar, et al. Ascorbic Acid ameliorates nicotine exposure induced impaired spatial memory performances in rats. West Indian Med J 2014; 63: 318-324.

23 Slotkin TA, Seidler FJ, Spindel ER. Prenatal nicotine exposure in rhesus monkeys compromises development of brainstem and cardiac monoamine pathways involved in perinatal adaptation and sudden infant death syndrome: amelioration by vitamin C. Neurotoxicol Teratol 2011; 33: 431-434.

24 Maritz GS, van Wyk G. Influence of maternal nicotine exposure on neonatal rat lung structure: protective effect of ascorbic acid. Comp Biochem Physiol C Pharmacol Toxicol Endocrinol 1997; 117: 159-165.

25 Proskocil BJ, Sekhon HS, Clark JA, et al. Vitamin C prevents the effects of prenatal nicotine on pulmonary function in newborn monkeys. Am J Respir Crit Care Med 2005; 171: 1032-1039.

26 McEvoy CT, Shorey-Kendrick LE, Milner K, et al. Vitamin C to pregnant smokers persistently improves infant airway function to 12 months of age: a randomised trial. Eur Respir J 2020; 56: 1902208.

27 McEvoy CT, Shorey-Kendrick LE, Milner K, et al. Oral Vitamin C (500 mg/d) to Pregnant Smokers Improves Infant Airway Function at 3 Months (VCSIP). A Randomized Trial. Am J Respir Crit Care Med 2019; 199: 1139-1147. 